\title{
Noncovalent Hydrogen Bonds Tune the Mechanical Properties of Phosphoester Polyethylene Mimics
}

\author{
Hisaschi T. Tee, ${ }^{\dagger}$ Kaloian Koynov, ${ }^{\dagger}$ Tobias Reichel, ${ }^{\dagger}$ and Frederik R. Wurm ${ }^{*}{ }^{\dagger}$ (]) \\ ${ }^{\dagger}$ Max-Planck-Institut für Polymerforschung, Ackermannweg 10, 55128 Mainz, Germany \\ ${ }^{\ddagger}$ Heraeus Medical, Philipp-Reis-Straße 8/13, 61273 Wehrheim, Germany
}

Supporting Information

ABSTRACT: Polyethylene mimics of semicrystalline polyphosphoesters (PPEs) with an adjustable amount of noncovalent cross-links were synthesized. Acyclic diene metathesis copolymerization of a phosphoric acid triester (M1) with a novel phosphoric acid diester monomer (M2) was achieved. PPEs with different co-monomer ratios and 0, 20, 40, and $100 \%$ of phosphodiester content were synthesized. The phosphodiester groups result in supramolecular interactions between the polymer chains, with the $\mathrm{P}-\mathrm{OH}$ functionality as an $\mathrm{H}$-bond donor and the $\mathrm{P}=\mathrm{O}$ group as an $\mathrm{H}$-bond acceptor. A library of unsaturated and saturated PPEs was prepared and analyzed in detail by NMR spectroscopy, size exclusion chromatography, differential scanning calorimetry, thermogravimetry, rheology, and stress-strain measurements. The introduction of the supramolecular cross-links into the aliphatic and hydrophobic PPEs showed a significant impact on the material properties: increased glass-transition and melting temperatures were observed and an increase in the storage modulus of the polymers was achieved. This specific combination of a flexible aliphatic backbone and a supramolecular H-bonding interaction between the chains was maximized in the homopolymer of the phosphodiester monomer, which featured additional properties, such as shape-memory properties, and polymer samples could be healed after cutting. The $\mathrm{P}-\mathrm{OH}$ groups also showed a strong adhesion toward metal surfaces, which was used together with the shape-memory function in a model device that responds to a temperature stimulus with shape change. This systematic variation of phosphodiesters/phosphotriesters in polyethylene mimics further underlines the versatility of the phosphorus chemistry to build up complex macromolecular architectures.

\section{INTRODUCTION}

Inspired by nature, supramolecular chemistry uses hydrogen bonding, ${ }^{1-4}$ metal-ligand interactions, ${ }^{5}$ or donor-acceptor $\pi-\pi$ stacking $^{6}$ to assemble small molecules or polymers into materials with an extensive range of properties. ${ }^{7}$ In nature, complex structures are generated by hydrogen bonding such as proteins, which fold into specific three-dimensional structures to enable their function, or DNA with hydrogen bonding between the nucleic acids, which plays a crucial role in the double-helical structure. ${ }^{8}$ The strength of a single hydrogen bond (H-bond) is ca. $10-40 \mathrm{~kJ} \mathrm{~mol}^{-1}$ relatively weak; however, multiple $\mathrm{H}$-bonds result in high cohesive energies, which can act as physical cross-links in polymer networks. Due to the temperature sensitivity of H-bonded networks, their viscoelasticity can be changed to give low-viscosity melts or more solidlike properties. However, by choice of the H-bonds, the material properties can be designed in advance due to weak $\mathrm{H}$-bonds having a fast bond exchange, which results in stimuli responsiveness, whereas strong $\mathrm{H}$-bonds having a retarded bond exchange leading to solidlike properties. Several technological concepts such as self-healing, ${ }^{9}$ shape-memory processes, $^{10}$ and dynamic energy dissipation ${ }^{11}$ have been achieved by the incorporation of $\mathrm{H}$-bonds into polymers. $\mathrm{H}$ - bonds alter or improve the mechanical properties of a polymer $^{12,13}$ and are not only crucial for industrially important polymers like polyurethanes or polyamides ${ }^{13-15}$ but have also been reported in several supramolecular polymers. ${ }^{16,17}$

We have been recently working on aliphatic polyethylene (PE) mimics based on P-containing aliphatic polymers. Such polyphosphoesters (PPEs) or polypyrophosphates crystallized similar to polyethylene but bring the potential to be degradable. ${ }^{18-20}$ In linear main-chain PPEs, two phosphoesters build the polymer backbone, whereas the pendant ester group can be used to tune their chemical functionality. ${ }^{21,22}$ Besides chemical functionality, herein we used the pendant chain to introduce physical cross-linking into a polyphosphoester PE mimic. Phosphodiester groups were installed into the polymer backbone, with the $\mathrm{P}-\mathrm{OH}$ functionality as an $\mathrm{H}$-bond donor and the $\mathrm{P}=\mathrm{O}$ group as an $\mathrm{H}$-bond acceptor. We report the synthesis of aliphatic PPEs with a variable amount of phosphodiesters and -triesters via acyclic diene metathesis (ADMET) polymerization of $\mathrm{A}_{2}$-type phosphodiester or

Received: April 11, 2019

Accepted: May 16, 2019

Published: May 28, 2019 


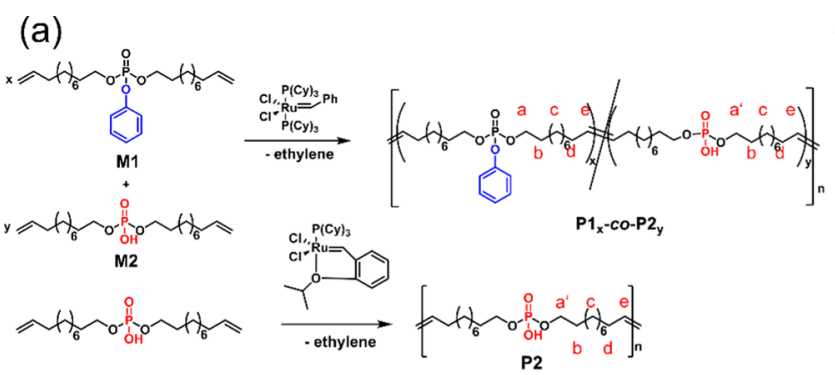

(c)

(b)

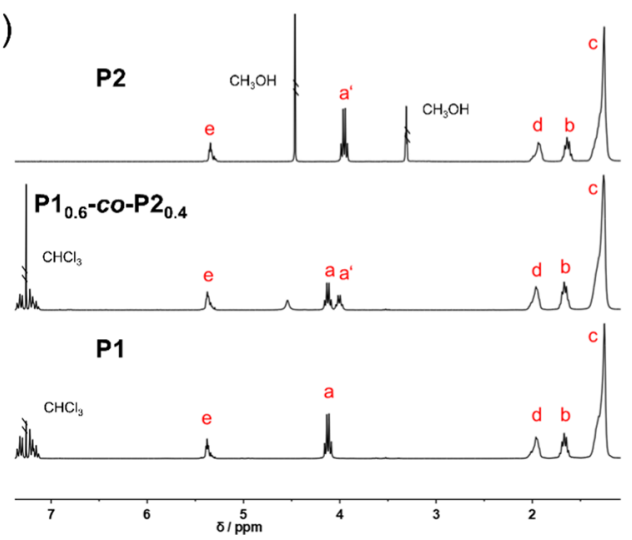

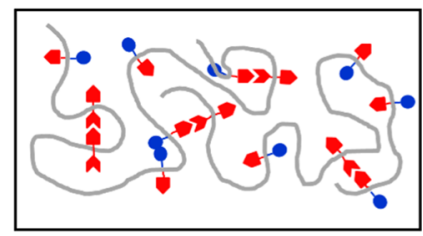

H-bonded Copolymers

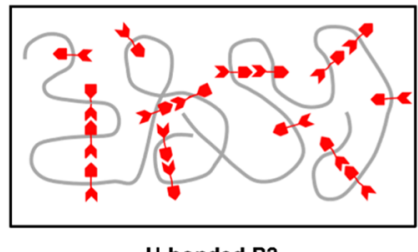

H-bonded P2

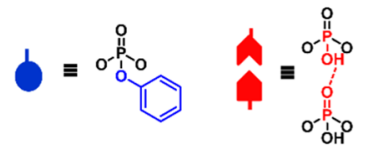

Figure 1. Synthesis of noncovalently cross-linked polyphosphoesters. (a) Synthesis of main-chain polyphosphodiesters (P2) and copolymers $\mathbf{P}(\mathbf{1 -}$ co-2) by acyclic diene metathesis polycondensation. (b) ${ }^{1} \mathrm{H}$ NMR spectra of P1, P2, and a copolymer $\mathbf{P}(\mathbf{1}$-co-2) with signal assignments. (c) Schematic representation of noncovalently cross-linked PPEs by $\mathrm{H}$-bonding between the $\mathrm{P}-\mathrm{OH}$ and $\mathrm{P}=\mathrm{O}$ groups.

-triester monomers. By the co-monomer ratio, the amount of $\mathrm{H}$-bonding groups in the main chain was adjusted to control the properties of the noncovalent polymer network. As ADMET polymerization produces unsaturated PPEs, with typically a low degree of crystallinity, hydrogenation can be performed to increase their crystallinity. ${ }^{23}$ In combination with the supramolecular H-bond interactions, this is another way to control the mechanical properties of the polymer networks that were studied herein by rheology. Depending on the amount of H-bonding cross-links, brittle or ductile materials with healing and shape-memory properties were obtained. This study expands the previous studies on aliphatic PE mimics to dynamic materials with noncovalent cross-linking, which broaden potential applications.

\section{RESULTS AND DISCUSSION}

Monomer and Polymer Syntheses. To study the influence of noncovalent/supramolecular cross-linking, two different phosphate monomers were prepared. Both monomers were equipped with two $C_{11}$ unsaturated alkyl chains for the linear ADMET polycondensation. $\mathbf{M 1}$ is a phosphotriester carrying a phenoxy side group, whereas M2 is a phosphodiester with the $\mathrm{P}-\mathrm{OH}$ side group, which is able to undergo $\mathrm{H}$ bonding. M1 was used by our group previously and was synthesized by esterification of phenyl dichlorophosphate with 10-undecen-1-ol in the presence of triethylamine. ${ }^{23}$ M2 was prepared by the reaction of phosphorus oxychloride with 2 equiv of 10-undecen-1-ol followed by hydrolysis of the remaining $\mathrm{P}-\mathrm{Cl}$ bond with water. The effect of $\mathrm{H}$-bonding on the properties of $\mathbf{M} 2$ can be already seen between both monomers. At room temperature, $\mathbf{M 1}$ is a viscous liquid, whereas M2 is a white solid.

The polymerization and copolymerization of both monomers were accomplished by acyclic diene metathesis
(ADMET) (co)polymerization (Figure 1a). Polymerization was conducted in bulk without the addition of the solvent with mechanical stirring. To adjust the number of physical crosslinks and thus to alter the mechanical properties, copolymers with different amounts of $\mathbf{M} 2$ were prepared: 0 mol \% (P1), 5 $\mathrm{mol} \%\left(\mathbf{P 1}-\mathrm{H}_{0.95}-\mathrm{co}-\mathbf{P 2}-\mathrm{H}_{\mathbf{0 . 0 5}}\right), 20 \mathrm{~mol} \%\left(\mathbf{P 1}-\mathrm{H}_{\mathbf{0 . 8 0}}\right.$-co-P2$\left.\mathbf{H}_{\mathbf{0 . 2 0}}\right)$, $40 \mathrm{~mol} \%\left(\mathbf{P 1}-\mathbf{H}_{\mathbf{0 . 6 0}}\right.$-co-P2-H $\left.\mathbf{H}_{\mathbf{0 . 4 0}}\right)$, or $100 \mathrm{~mol} \%$ (P2). Copolymers with $\leq 40 \mathrm{~mol} \% \mathbf{M} 2$ were prepared with Grubbs first-generation catalyst. Copolymers with higher amounts of M2 were obtained only with Hoveyda-Grubbs first-generation catalyst. As the viscosity increased during the polymerization, the temperature was increased from $65^{\circ} \mathrm{C}$ up to $90{ }^{\circ} \mathrm{C} . \mathbf{P}\left(\mathbf{1}_{x^{-}}\right.$ co-2 $2_{y}$ ) with $x \leq 40 \mathrm{~mol} \%$ were obtained as viscous oils at room temperature. To increase their crystallinity, hydrogenation with $10 \% \mathrm{Pd} / \mathrm{C}$ was performed.

${ }^{1} \mathrm{H}$ NMR and ${ }^{31} \mathrm{P}$ NMR were used to confirm the composition of copolymers and showed that the monomer composition used in the synthesis is found in the polymer product. Figure $1 \mathrm{~b}$ shows the characteristic shift for the protons in the backbone next to the phosphates, which allows the determination of the monomer ratio. For all polymers, gel permeation chromatography (GPC) showed successful polymerization and molar mass dispersities of ca. 2, as expected for a linear polycondensation, and apparent molar masses (vs PS standards) between $M_{\mathrm{n}}=4700$ and $11400 \mathrm{~g} \mathrm{~mol}^{-1}$. For GPC measurement of $\mathbf{P 2}$, the $\mathrm{P}-\mathrm{OH}$ groups were converted to the methyl esters by esterification with trimethylsilyldiazomethane to ensure solubilization in tetrahydrofuran (THF) (the ${ }^{1} \mathrm{H}$ NMR spectra of the methoxylated $\mathbf{P 2}$ showed a characteristic doublet at 3.75 ppm, proving successful esterification; cf. Figure S16). Also, the other copolymers were transformed into the methyl ester and measured on the GPC, which increased their apparent molar masses and probably increased their hydrodynamic radius after esterification (cf. Table 1). 
Table 1. Characterization Data of the Saturated Polyphosphoesters Prepared in This Study

\begin{tabular}{|c|c|c|c|c|c|c|c|c|c|}
\hline \# & $\mathrm{mol} \% \mathrm{M} 2$ & $M_{\mathrm{n}}{ }^{a} / \mathrm{kg} \mathrm{mol}^{-1}$ & $M_{\mathrm{w}} / M_{\mathrm{n}}$ & $M_{\mathrm{n}}^{b} / \mathrm{kg} \mathrm{mol}^{-1}$ & $M_{\mathrm{w}} / M_{\mathrm{n}}$ & $T_{\mathrm{m}}{ }^{c} /{ }^{\circ} \mathrm{C}$ & $T_{\mathrm{c}}{ }^{c} /{ }^{\circ} \mathrm{C}$ & $\Delta H_{\mathrm{m}}{ }^{c} / \mathrm{J} \mathrm{g}^{-1}$ & crystallinity $^{d} / \%$ \\
\hline P1 & 0 & 8.0 & 2.3 & n.d. & n.d. & 44 & $40 ; 24$ & 63 & 22 \\
\hline$\left(\mathrm{P} 1-\mathrm{H}_{0.95}-c o-\mathrm{P} 2-\mathrm{H}_{0.05}\right)$ & 5 & 6.5 & 2.3 & n.d. & n.d. & 46 & $41 ; 27$ & 80 & 27 \\
\hline$\left(\mathrm{P} 1-\mathrm{H}_{0.80^{-}}-c o-\mathrm{P} 2-\mathrm{H}_{0.20}\right)$ & 20 & 8.4 & 2.2 & 11.4 & 2.3 & $48 ; 53$ & 48 & 54 & 18 \\
\hline$\left(\mathrm{P} 1-\mathrm{H}_{0.60}-c 0-\mathrm{P} 2-\mathrm{H}_{0.40}\right)$ & 40 & 4.7 & 2.0 & 8.4 & 2.8 & $51 ; 60$ & 54 & 50 & 17 \\
\hline P2 & $100_{\text {unsat.* }}$ & n.d. & n.d. & 9.8 & 1.8 & $51 ; 80$ & 25 & 40 & 14 \\
\hline P2-H & 100 & n.d. & n.d. & n.d. & n.d. & 93 & 89 & 110 & 37 \\
\hline
\end{tabular}

${ }^{a}$ Determined by GPC in THF versus polystyrene standards. ${ }^{b}$ Determined by GPC in THF versus polystyrene standards after methoxylation. ${ }^{c}$ Determined by DSC with a heating/cooling rate of $10 \mathrm{~K} \mathrm{~min}^{-1}$. Peak $T_{\mathrm{m}}$ determined from the second heating run. ${ }^{d}$ From DSC measurements, calculated versus $100 \%$ crystalline polyethylene $\left(293 \mathrm{~J} \mathrm{~g}^{-1}\right) .{ }^{25} *$ unsaturated polymer.

Two melting peaks were observed with $\mathrm{P}-\mathrm{OH}$ functionality above $20 \%$, which were reported for other polymers prepared by ADMET previously. ${ }^{26}$ The melting temperature increased significantly with more $\mathrm{P}-\mathrm{OH}$ groups incorporated into the polymers. The crystallinity determined by differential scanning calorimetry (DSC) shows no clear trend with increasing $\mathrm{H}$ bonding, and X-ray diffractograms (XRD) (Figure S27) revealed a similar degree of crystallinity and crystal structure for $\mathbf{P}\left(\mathbf{1}-\mathrm{H}_{x}-\mathbf{c o}-\mathbf{2}-\mathrm{H}_{y}\right)$ (with $y \leq 0.4$ ). Thermogravimetric analysis (TGA) indicated thermal stability between 260 and $300{ }^{\circ} \mathrm{C}$ (Figure S26) with a relative high char yield for P2, which could make this polymer additionally an interesting flame retardant. ${ }^{27}$

Mechanical Properties. Tensile Stress-Strain Measurements. From the thermal characterization, the influence of the number of noncovalent cross-links on the material properties was already obvious. The effect of increasing $\mathrm{H}$-bonding groups on the stress-strain behavior of PPEs was investigated. For P1-H and $\mathbf{P 1}-\mathbf{H}_{\mathbf{0 . 9 5}}-\mathbf{c o}-\mathbf{P 2}-\mathbf{H}_{\mathbf{0 . 0 5}}$, the polymer films were too brittle to conduct a reproducible measurement with the dog-bone specimen. P1- $\mathbf{H}_{0.80}-$ co-P2- $\mathbf{H}_{0.20}$ and P1- $\mathbf{H}_{0.60}$-co-P2$\mathbf{H}_{\mathbf{0 . 4 0}}$ polymer films and dog-bone specimen were still relatively brittle, but already during handling, higher flexibility was obvious. Still, relatively low elongations ranging from $7.3 \pm 0.8$ to $9.5 \pm 0.6 \%$ were achieved in the stress-strain test before breaking, as expected for a brittle semicrystalline polymer (Figure 2a). P1- $\mathbf{H}_{0.80}-$ co-P2- $\mathbf{H}_{0.20}$ and $\mathbf{P 1}-\mathbf{H}_{0.60}-$ co-P2- $-\mathbf{H}_{0.40}$ showed a relatively low material stiffness with a Young's modulus of $0.8 \pm 0.2 \mathrm{GPa}$. In contrast, P2-H exhibited an average elongation at break of $100 \pm 30 \%$, with a yield strength $\left(\sigma_{y}\right)$ of $20.5 \mathrm{MPa}$, as more noncovalent interactions are present in this polymer (Figure 2b). Interestingly, the unsaturated analogue P2 showed the highest elongation at break of the investigated samples with $640 \pm 45 \%$. The yield strength of 8.6 $\mathrm{MPa}$, however, was lower due to the decreased chain packing of the unsaturated backbone (with cis and trans double bonds). P2-H seemed to be stronger, probably due to the higher crystallinity and chain arrangement, whereas P2 was less strong but more ductile and undergoes strain crystallization after passing the yield point. This is in agreement with the measured Young's modulus values of $0.8 \pm 0.1 \mathrm{GPa}$ for P2 and $1.2 \pm 0.2 \mathrm{GPa}$ for $\mathbf{P 2}-\mathbf{H}$, indicating a significant higher material stiffness for P2-H.

Rheological Measurements. To probe the softening and melting behavior of the polymers, we measured the temperature dependencies of their storage $G^{\prime}$ and loss $G^{\prime \prime}$ moduli in the range of below the glass transition to a temperature above the melting transition. The temperature sweeps in Figure 3 show that a higher $\mathrm{P}-\mathrm{OH}$ amount in the copolymers led to an increase of both glass-transition and melting-transition temper-
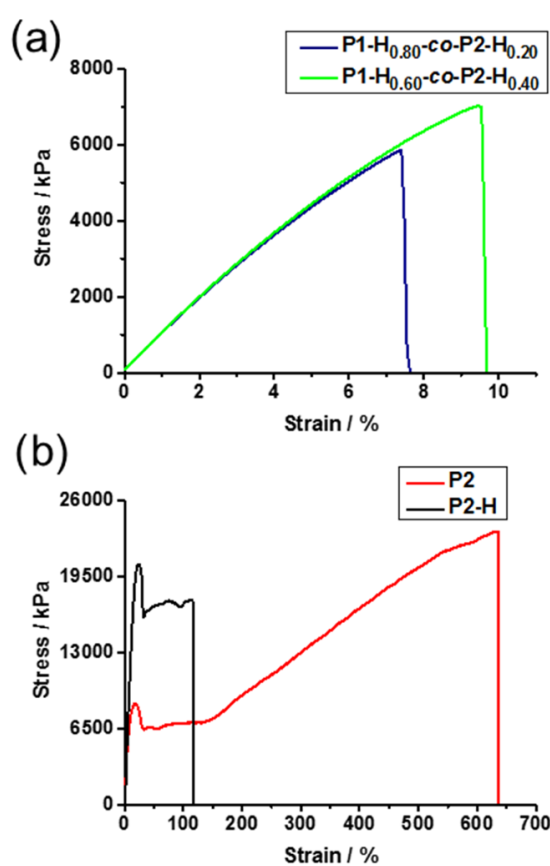

Figure 2. Tensile stress-strain curves of (a) $\mathbf{P 1}-\mathbf{H}_{0.80}-\mathbf{c o}-\mathbf{P 2}-\mathbf{H}_{\mathbf{0 . 2 0}}$ and $\mathbf{P 1}-\mathrm{H}_{0.60}-$ co $-\mathbf{P 2}-\mathrm{H}_{0.40}$ and (b) P2 and P2-H.

atures. Even the unsaturated P2, with the double bonds still in the backbone, had a $T_{\mathrm{m}}$ of ca. $50{ }^{\circ} \mathrm{C}$ resulting in a solid material at room temperature, which was not the case for the unsaturated PPEs with a lower amount of hydrogen-bonding groups.

It is interesting to consider and compare the moduli measured at temperatures above the melting temperature where the crystalline parts of the polymers are molten and the polymer chains are able to move. For P1-H, $G^{\prime}$ is much lower than $G^{\prime \prime}$ and it shows much lower viscosity compared to P1-

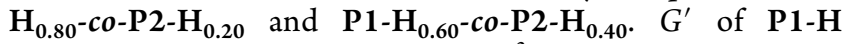
without any $\mathrm{H}$-bonding is around $10^{3}$ times lower compared to $G^{\prime}$ of $\mathbf{P 1}-\mathbf{H}_{0.60}-\mathrm{co}-\mathbf{P 2}-\mathbf{H}_{\mathbf{0 . 4 0}}$, proving that $\mathbf{P 1}-\mathbf{H}$ has more fluidlike properties and less elasticity. Even though $G^{\prime}$ of P1$\mathbf{H}_{0.60}$-co-P2- $\mathbf{H}_{0.40}$ is much higher due to the H-bonding, $\tan \delta$ $\left(G^{\prime \prime} / G^{\prime}\right)$ is still $<1$, indicating a predominantly fluidlike material. Only when the physical cross-linking was increased to $100 \mathrm{~mol} \%$ of monomer 2, a distinct change in the rheological behavior was detected (Figure 3b). Unlike the polymers without H-bonding or lower H-bonding content, $G^{\prime}$ for $\mathbf{P 2}$ is larger than $G^{\prime \prime}$ at temperatures above the melting transition. Furthermore, the values of $G^{\prime}$ of $\mathbf{P 2}$ were ca. 100 times higher than for $\mathbf{P 1}-\mathbf{H}_{\mathbf{0 . 6 0}}-\mathbf{c o}-\mathbf{P 2}-\mathbf{H}_{\mathbf{0 . 4 0}}$ and ca. $10^{5}$ times larger than for $\mathbf{P 1}-\mathbf{H}$. Over the entire temperature range, $G^{\prime}$ is 
(a)
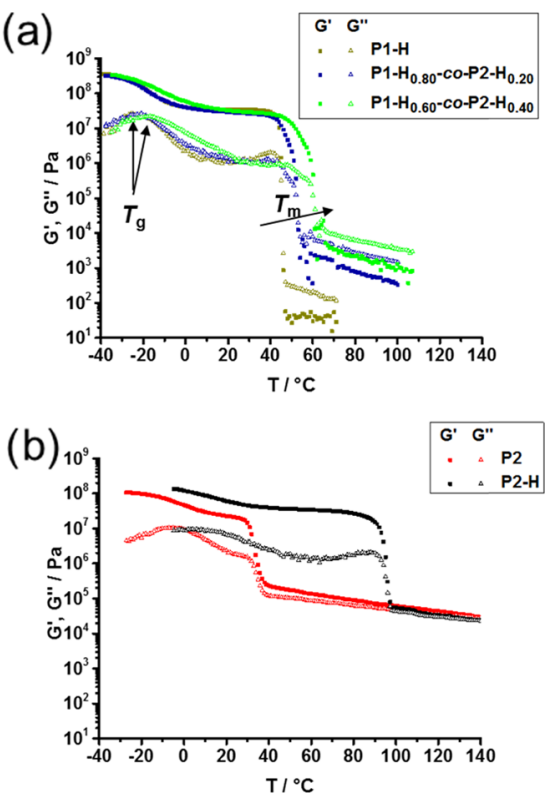

Figure 3. Temperature dependencies of the storage $G^{\prime}$ and loss $G^{\prime \prime}$ moduli measured on heating from below $T_{\mathrm{g}}$ to above $T_{\mathrm{m}}$. (a) P1-H, P1- $\mathrm{H}_{0.80}-c o-\mathbf{P} 2-\mathrm{H}_{0.20}$ and P1- $\mathrm{H}_{0.60}-c o-\mathbf{P 2}-\mathrm{H}_{0.40}$. (b) P2 and P2-H.

larger than $G^{\prime \prime}$ showing the strong H-bonding of the phosphates in P2, which resulted in a solidlike behavior even up to $140{ }^{\circ} \mathrm{C}$. After hydrogenation of P2, the melting temperature was further increased by more than $100 \%$ to ca. $110^{\circ} \mathrm{C}$. P2-H has slightly higher $G^{\prime}$ and $G^{\prime \prime}$ values compared to $\mathbf{P 2}$ below $30{ }^{\circ} \mathrm{C}$ due to the more crystalline backbone; however, after melting of $\mathbf{P 2}-\mathbf{H}$, both polymers show similar values for $G^{\prime}$ and $G^{\prime \prime}$. The dependency of $T_{\mathrm{m}}, T_{\mathrm{g}}$, and $G^{\prime}$ on the amount of H-bonding groups is summarized in Figure 4. A linear increase of thermal properties and storage modulus can be observed for copolymers with $\mathrm{P}-\mathrm{OH}$ amounts up to $80 \%$, whereas the cumulative $\mathrm{H}$-bonding in the homopolymer P2-H led to an extraordinary increase of $T_{\mathrm{g}}, T_{\mathrm{m}}$, and $G^{\prime}$ values.

Shape-Memory and Healing Properties of P2 and P2-H. The majority of shape-memory polymers have phasesegregated morphologies consisting of soft and hard domains. The soft domains will crystallize when cooled under a strained state, and under heating, those soft domains will melt and trigger the shape-memory transition. ${ }^{28}$ Irradiation with light $^{29,30}$ and heating above the polymer's glass transition ${ }^{31}$ are other triggers for shape-memory transitions. In P2, reversible hydrogen-bond association is combined with crystallization of the aliphatic chains, in which the strained state can be stabilized by forming a physical cross-linking when cooled due to the slow $\mathrm{H}$-bond exchange as well as crystallization of the soft domains. The release of the strained state is achieved by heating above the melting temperature of the crystalline domains and by a fast $\mathrm{H}$-bond exchange with heating. ${ }^{32}$ A proposed mechanism for the shape memory and self-healing due to main-chain H-bonding is shown in Figure 5. PPEs with lower amounts of M2 did not show any shapememory properties. Furthermore, shape-memory properties were found only for $\mathbf{P} 2$ and not for $\mathbf{P 2}-\mathbf{H}$. To assess the shapememory properties of $\mathrm{P} 2$, a dog-bone specimen was prepared (Figure 5a). After heating to $70^{\circ} \mathrm{C}$, the shape was changed by wrapping it around an NMR tube and when allowed to cool, the shape was retained. On heating this new shaped material again to more than $70{ }^{\circ} \mathrm{C}$, the original shape was almost
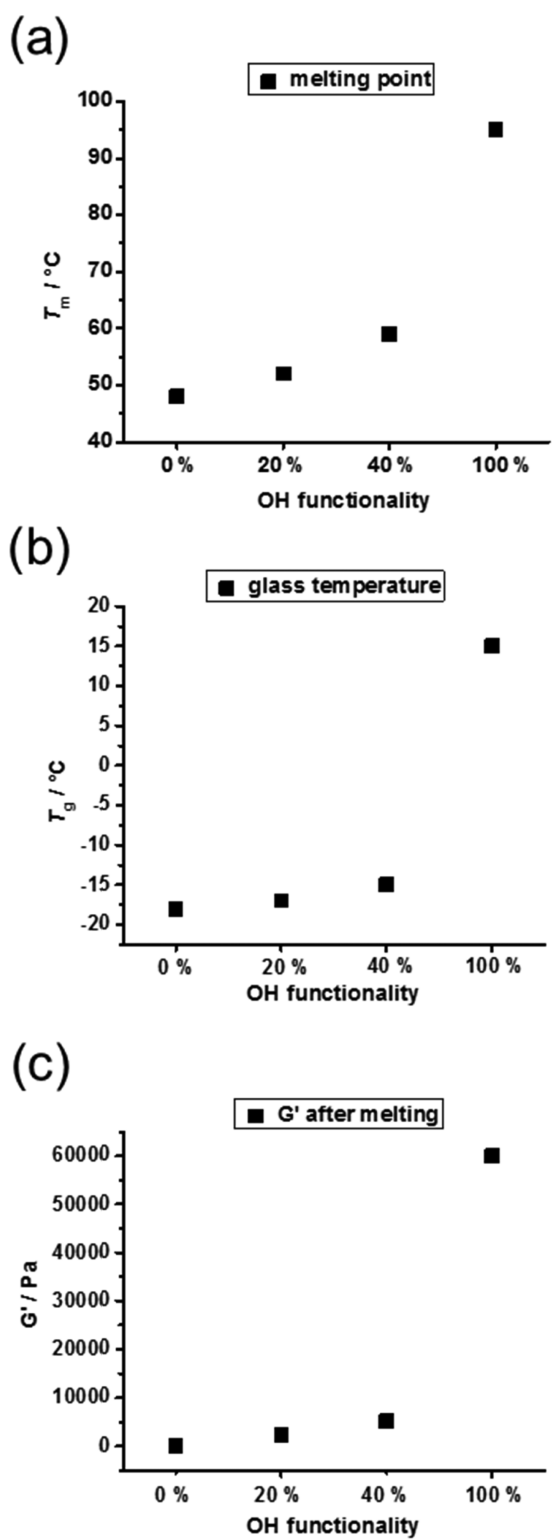

Figure 4. Variation of thermal transition temperatures and $G^{\prime}$ after melting with the increasing hydrogen-bonding groups of saturated PPEs. (a) Glass-transition temperature. (b) Melting-transition temperature. (c) $G^{\prime}$ after melting.

completely recovered (Figure 5a). The difference in the melting points of $\mathbf{P 2}$ and $\mathbf{P 2}-\mathbf{H}$ (Figure $6 \mathrm{~b}$ ) and a certain necessary amount of $\mathrm{H}$-bonding groups support our proposed mechanism in Figure 5. The strained shape is pinned by the crystallization of our cooling PPEs and by a slower H-bonding exchange. When heated above $T_{\mathrm{m}}$, the crystalline parts are melting and the H-bonds can trigger the shape memory. Due to the presence of noncovalent cross-links in the material, P2 could also be healed by heating a cut piece above the melting temperature of the crystalline domains (Figure $5 \mathrm{~b}$ ). For healing, specimens with different diameters were used to allow for easily distinguished interfaces. The cut pieces were softened at $100{ }^{\circ} \mathrm{C}$, reattached, and then left to heal at $100{ }^{\circ} \mathrm{C}$ for $0.5 \mathrm{~h}$. The healed polymer showed the same stretching as the original polymer cylinders (Figure $5 \mathrm{~b}$ ).

The healing efficiency of $\mathbf{P 2}$ was further analyzed by tensile stress-strain measurements of dog-bone specimen of $\mathbf{P 2}$ (as 
(a)

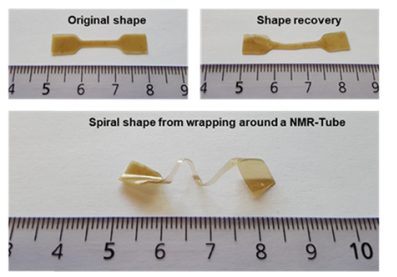

(b)

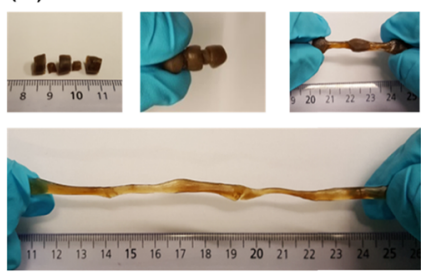

(c)

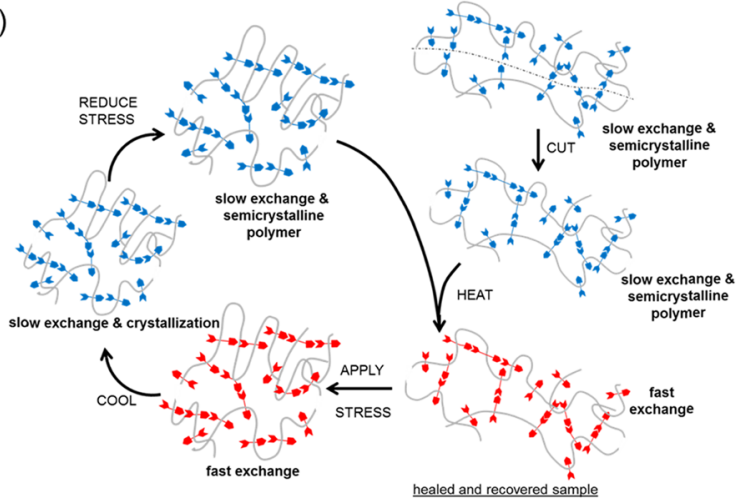

Figure 5. (a) Shape-memory properties of P2. A dog-bone sample was wrapped and stretched around an NMR tube at $70{ }^{\circ} \mathrm{C}$ to give a strained spiral shape, which maintained its shape at room temperature. The original shape was almost recovered after heating at $70{ }^{\circ} \mathrm{C}$. (b) Healing properties of P2. Cylindrical polymer specimens with different diameters were used to visualize the interfaces. Healed material was obtained after pressing multiple samples at $100{ }^{\circ} \mathrm{C}$ together. After healing at $100{ }^{\circ} \mathrm{C}$ for $30 \mathrm{~min}$, the healed material showed similar elasticity. (c) Proposed self-healing and shapememory mechanism with breaking and re-association of hydrogen bonds with temperature change.

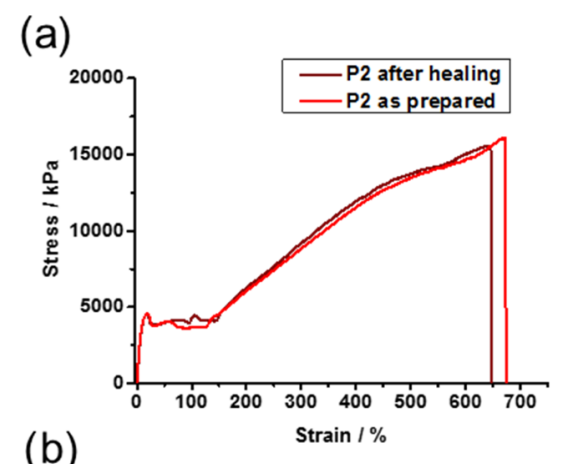

(b)

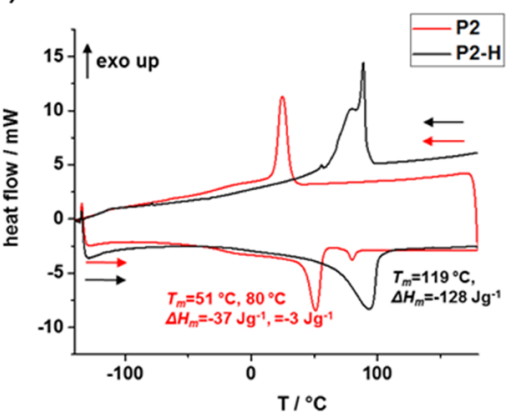

Figure 6. (a) Tensile stress-strain curves measured for samples of P2 before and after healing. (b) DSC of P2 and P2-H with a heating (second run) and cooling rate of $10 \mathrm{~K} \mathrm{~min}^{-1}$.

prepared) and P2 after healing. Elongation of ca. 640\% was achieved for the "as prepared" specimen. After cutting the dog- bone samples of $\mathbf{P 2}$ and healing at $100{ }^{\circ} \mathrm{C}$, the ultimate elongation was almost recovered with $610 \pm 20 \%$ (Figure 6a). In contrast, healing of a cut sample of $\mathbf{P 2}-\mathbf{H}$ was not successful probably due to the higher melting point (Figure 6b). In P2, the combination of a relatively low melting point with the multiple H-bonds, which avoid the flow of the polymer, allows the healing to take place efficiently above the melting. In the molten polymer, the chains are mobile and the H-bonds exchange fast, allowing the movement of polymer chains and the formation of new H-bonds. Once the temperature drops, $\mathrm{H}$-bonds will exchange slower and the polymer will crystallize resulting in a completely healed material.

Combination of Metal Adhesion and Shape Memory. The adhesion properties of phosphoric acid esters on hydroxyapatite $^{33,34}$ or metals like alumina ${ }^{35}$ are well known and therefore these materials are often used as dental adhesives or metal coatings. Shear lap test on alumina was conducted for the herein-prepared polymers and underlined the strong adhesion of $\mathbf{P 2}$ with a tension of $22.6 \mathrm{~N} \mathrm{~mm}^{-2}$ (Figure S28). Figure S29 shows the fractures after the shear lap test; all polymers except P2 showed an adhesion fracture, which is mostly an undesired fracture. P2 showed a hybrid fracture, which is desired for many applications due to the balance of adhesion and cohesion strength. These adhesion properties were combined with the shape-recovery process in an easy device that responds to a temperature stimulus with a shape change: $\mathbf{P 2}$ was brought into a rectangular shape and used to glue two pieces of steel together. On these metal plates, a circuit with an light-emitting diode (LED) was installed. This closed circuit was opened, i.e., disconnected by changing the shape of $\mathbf{P 2}$ after heating. In the stressed state, the metal plates are connected (Figure 7 top) and the LED is switched on.

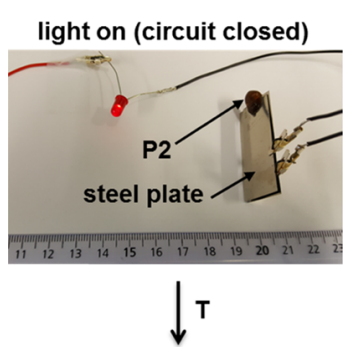

light off (circuit open)

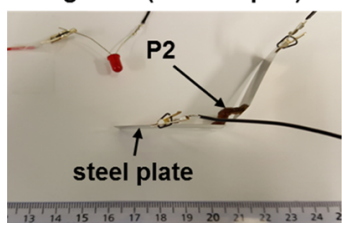

Figure 7. Visualization of the shape-memory and adhesive properties of P2: P2 was glued to two metal plates after shape deformation and a circuit was closed to light an LED. After shape recovery, the metal plates were moved apart to disconnect the circuit.

When the polymer glue is heated above the melting point, the shape-memory transition was triggered and the polymer disconnected the circuit by moving the two metal plates away from each other (Figure 7 bottom). This combination of adhesion and shape-memory properties might be further expanded to more sophisticated devices or smart materials for tissue engineering (e.g., for an implant or bone adhesion). 


\section{SUMMARY}

We prepared noncovalently cross-linked polyphosphoester PE mimics. PPEs with a variable number of phosphodiester units were prepared by ADMET polycondensation. Polymers with $40 \%$ or lower $\mathrm{P}-\mathrm{OH}$ functionality were brittle due to the low amount of noncovalent cross-linking. However, they showed linear enhanced viscosity above the melting temperature in rheology with increased H-bonding. Furthermore, PPEs with 20 and $40 \% \mathrm{H}$-bonding functionality were more flexible and their polymer films could easily be processed to the dog-bone specimen, whereas PPEs with no H-bonding or just $5 \% \mathrm{H}$ bonding functionality showed low flexibility. The homopolymer of M2 carries in every mononer unit the H-bonding functionality, which led to the highest values for tensile stressstrain and thermal transitions. In addition, P2 exhibited healing, shape-memory properties, and strong adhesion to metal surfaces. With the adjustable content of noncovalent cross-linking in synthesis, the polymers exhibit tunable mechanical properties depending on $\mathrm{P}-\mathrm{OH}$ functionality in the main chain. Combining the properties of PPEs like the degradability, potential inherent bone adhesion, and osteoinductive potential of phosphate-containing polymers with properties arising from the reversible cross-linking of hydrogen bonds, these PPEs might find application as novel materials for bone tissue regeneration. Furthermore, such materials might also be interesting for flame-retardant coatings or adhesives.

\section{EXPERIMENTAL SECTION}

Materials. All solvents and chemicals were purchased from Sigma-Aldrich, Acros Organics, or Fluka and used as received unless otherwise stated. Triethylamine was distilled from calcium hydride and stored over molecular sieves $(4 \AA)$ under argon prior to use. Dry solvents were purchased from Acros Organics or Sigma-Aldrich and stored with a septum and over molecular sieves. Deuterated solvents, Grubbs first-generation catalyst, Hoveyda-Grubbs first-generation catalyst, and $\mathrm{Pd} / \mathrm{C}$ (10 wt \%) were purchased from Sigma-Aldrich and used as received.

Methods. SEC measurements were performed in THF with a PSS SecCurity system (Agilent Technologies 1260 Infinity). Sample injection was performed by a 1260 -ALS autosampler (Waters) at $30{ }^{\circ} \mathrm{C}$. SDV columns (PSS) with dimensions of $300 \times 80 \mathrm{~mm}^{2} ; 10 \mu \mathrm{m}$ particle size; and pore sizes of 106,104 , and $500 \AA$ a were employed. The DRI Shodex RI-101 detector (ERC) and UV-vis 1260-VWD detector (Agilent) were used for detection. Calibration was achieved using polystyrene standards provided by Polymer Standards Service. For nuclear magnetic resonance analysis, ${ }^{1} \mathrm{H},{ }^{13} \mathrm{C}$, and ${ }^{31} \mathrm{P}$ NMR spectra of the monomers and polymers were recorded on a Bruker AVANCE III 300, 500, or $700 \mathrm{MHz}$ spectrometer. All spectra were recorded in $\mathrm{CDCl}_{3}, \mathrm{CDCl}_{3} / \mathrm{MeOD}$ (7:3), or pyridine- $d_{5}$ at $298 \mathrm{~K}$. The spectra were calibrated against the solvent signal and analyzed using MestReNova 8 from Mestrelab Research S.L. The thermal properties of the synthesized polymers have been measured by differential scanning calorimetry (DSC) on a Mettler Toledo DSC 823 calorimeter. Three scanning cycles of heating-cooling were performed in an $\mathrm{N}_{2}$ atmosphere with a heating and cooling rate of $10{ }^{\circ} \mathrm{C} \mathrm{min}{ }^{-1}$. TGA was carried out on a Mettler Toledo ThermoSTAR TGA/SDTA 851Thermowaage in a nitrogen atmosphere. The heating rate was $10{ }^{\circ} \mathrm{C} \mathrm{min}-1$ in a temperature range of 25 to $600-900{ }^{\circ} \mathrm{C}$. Fourier-transform infrared spectra were recorded in trans- mission mode accomplished with a Bruker Tensor II (Platinum ATR). Rheology experiments were performed using an Advanced Rheometric Expansion System (ARES, Rheometric Scientific). Plate-plate geometry was used with plate diameters of $6 \mathrm{~mm}$ and the gap between plates of $1 \mathrm{~mm}$. The experiments were conducted under a dry nitrogen atmosphere. Oscillatory shear deformation was applied under conditions of controlled deformation amplitude, which was kept in the range of the linear viscoelastic response of the studied samples. The temperature dependencies of the storage $G^{\prime}$ and loss $G^{\prime \prime}$ moduli were determined at a heating rate of 2 ${ }^{\circ} \mathrm{C} \mathrm{min}^{-1}$ and a constant deformation frequency of $10 \mathrm{rad} \mathrm{s}^{-1}$. Stress-strain behavior was studied using a Zwick Z005 universal testing machine equipped with a $50 \mathrm{~N}$ force sensor and $200 \mathrm{~N}$ clamping jaws. Dog-bone-shaped samples (with 13 $\mathrm{mm}$ gauge length and $2 \mathrm{~mm}$ width) were cut from compression-mold films. Samples were strained at room temperature and an extension rate of $10 \mathrm{~mm} \mathrm{~min}^{-1}$. For studying the healing properties, dog-bone samples were cut with a knife in the middle. The pieces were softened at $60{ }^{\circ} \mathrm{C}$ and reassembled manually and left for $12 \mathrm{~h}$ at $100{ }^{\circ} \mathrm{C}$ before tensile testing.

Monomer Syntheses. Bis-(undec-10-en-1-yl) Phenyl Phosphate (M1). A $500 \mathrm{~mL}$ Schlenk flask, equipped with a stirring bar and a dropping funnel, was charged with phenyl dichlorophosphate $(60 \mathrm{~g}, 0.28 \mathrm{~mol})$, dissolved in dry dichloromethane $(150 \mathrm{~mL})$ under an argon atmosphere. The solution was cooled to $0{ }^{\circ} \mathrm{C}$ with an ice bath. Dry dichloromethane $(50 \mathrm{~mL})$ and 1.8 equiv of triethylamine $(71$ $\mathrm{mL}, 0.51 \mathrm{~mol})$ and $101.22 \mathrm{~mL}(0.51 \mathrm{~mol})$ of 10 -undecen-1-ol were added over a period of about $1 \mathrm{~h}$ via the dropping funnel. After the addition, 0.01 equiv of 4- $\mathrm{N}, \mathrm{N}$-dimethylaminopyridine $(0.34 \mathrm{~g})$ were added and the reaction mixture was stirred overnight at room temperature. The crude mixture was concentrated at reduced pressure, dissolved in diethyl ether, and filtered. The organic phase was washed twice with $10 \%$ aqueous hydrochloric acid $(\mathrm{HCl})$ solution and twice with brine. The organic layer was dried over sodium sulfate, filtered, concentrated at reduced pressure, and purified by chromatography over neutral alumina using dichloromethane as an eluent to give an off-white viscous oil [yield: $70.4 \%, R_{f}\left(\mathrm{AlO}_{x}\right): 0.9$ $\left.\left(\mathrm{CH}_{2} \mathrm{Cl}_{2}\right)\right] .{ }^{1} \mathrm{H}$ NMR $\left(300 \mathrm{MHz}, \mathrm{CDCl}_{3}, 298 \mathrm{~K}\right): \delta=7.37-$ $7.27(\mathrm{~m}, 2 \mathrm{H}), 7.24-7.10(\mathrm{~m}, 3 \mathrm{H}), 5.90-5.70(\mathrm{ddt}, J=18 \mathrm{~Hz}$, $12 \mathrm{~Hz}, 6 \mathrm{~Hz}, 2 \mathrm{H}), 5.06-4.86(\mathrm{~m}, 4 \mathrm{H}), 4.20-4.04(\mathrm{~m}, 4 \mathrm{H})$, $2.10-1.95(\mathrm{~m}, 4 \mathrm{H}), 1.74-1.60(\mathrm{~m}, 4 \mathrm{H}), 1.46-1.16(\mathrm{~m}, 24 \mathrm{H})$ ppm. ${ }^{13} \mathrm{C}$ NMR $\left(75 \mathrm{MHz}, \mathrm{CDCl}_{3}, 298 \mathrm{~K}\right) \delta=139.11,129.63$, $124.88,119.99,119.93,114.15,68.56,68.48,33.78,30.25$, $30.16,29.41,29.36,29.08,29.06,28.90,25.36 \mathrm{ppm} .{ }^{31} \mathrm{P}\{\mathrm{H}\}$ $\operatorname{NMR}\left(121 \mathrm{MHz}, \mathrm{CDCl}_{3}, 298 \mathrm{~K}\right): \delta=-6.10 \mathrm{ppm}$.

Bis-(undec-10-en-1-yl) Phosphate (M2). A $500 \mathrm{~mL}$ Schlenk flask, equipped with a stirring bar and a dropping funnel, was charged with phosphorus oxychloride $(26.87 \mathrm{~g}, 0.18 \mathrm{~mol})$, dissolved in dry dichloromethane $(60 \mathrm{~mL})$ under an argon atmosphere. The solution was cooled to $0{ }^{\circ} \mathrm{C}$ with an ice bath. Dry dichloromethane $(40 \mathrm{~mL})$ and 2 equiv of triethylamine $(48.59 \mathrm{~mL}, 0.36 \mathrm{~mol})$ and 1.99 equiv $(70.05 \mathrm{~mL}, 0.36 \mathrm{~mol})$ of 10-undecen-1-ol were added over a period of about $1 \mathrm{~h}$ via the dropping funnel. After stirring overnight, the precipitated triethylammonium hydrochloride was removed by filtration. The filtrate containing the dialkylene chlorophosphate in dichloromethane was stirred vigorously, and an excess of water (ca. $100 \mathrm{~mL}$ ) was added to the mixture. The acidic aqueous phase was exchanged every day with fresh water until the 
reaction was finished. The reaction was acidified until phase separation occurred. The organic layer was separated from water and dried with $\mathrm{Na}_{2} \mathrm{SO}_{4}$, and the dichloromethane was evaporated in vacuo. The viscous residue was dissolved in hexane $(100 \mathrm{~mL})$ at room temperature and kept at $-20{ }^{\circ} \mathrm{C}$ to allow precipitation. The product was filtered and washed with cold hexane, and a colorless solid was obtained (yield: $86 \%$, $63.30 \mathrm{~g}) .{ }^{1} \mathrm{H}$ NMR $\left(250 \mathrm{MHz}, \mathrm{CDCl}_{3}, 298 \mathrm{~K}\right): \delta=5.91-5.71$ (ddt, $J=18 \mathrm{~Hz}, 12 \mathrm{~Hz} 6 \mathrm{~Hz}, 2 \mathrm{H}), 5.05-4.87$ (m, 2H), 4.08$3.95(\mathrm{q}, J=6 \mathrm{~Hz}, 4 \mathrm{H}), 2.11-1.96(\mathrm{~m}, 4 \mathrm{H}), 1.76-1.59(\mathrm{~m}$, $4 \mathrm{H}), 1.45-1.19(\mathrm{~m}, 24 \mathrm{H})$ ppm. ${ }^{13} \mathrm{C}$ NMR $(75 \mathrm{MHz}$, chloroform-d) $\delta=139.17,114.13,67.72,67.65,33.80,30.23$, $30.13,29.47,29.41,29.15,29.11,28.92,25.43$ ppm. ${ }^{31} \mathrm{P}\{\mathrm{H}\}$ NMR (121 MHz, $\left.\mathrm{CDCl}_{3}, 298 \mathrm{~K}\right): \delta=1.09 \mathrm{ppm}$.

Representative Procedure for the ADMET Bulk Polymerization of M1 and Copolymerization with M2 up to $40 \%$. $P 1$. In a vacuum reactor, M1 (100 g) and for copolymers the analogue equivalent of $\mathbf{M} 2$ and the Grubbs first-generation catalyst $(0.3 \mathrm{~mol} \%)$ were mixed under an argon atmosphere. Polymerization was carried out at reduced pressure [first membrane pump ( $5 \mathrm{~h}, 50 \mathrm{mbar}$ ) and then oil pump (1 mbar)] to remove ethylene gas evolving during the metathesis reaction at $65{ }^{\circ} \mathrm{C}$ for $1 \mathrm{~h}$ and $85{ }^{\circ} \mathrm{C}$ for $16-48 \mathrm{~h}$. The crude mixture was dissolved in $\mathrm{CH}_{2} \mathrm{Cl}_{2}$ and treated with tris(hydroxymethyl)phosphine (10 equiv with respect to the catalyst) and $2 \mathrm{~mL}$ of $\mathrm{Et}_{3} \mathrm{~N}$. After being stirred for $1 \mathrm{~h}$, water was added in the same volume to the organic phase and the solution was stirred overnight. The organic layer was washed twice with $5 \%$ aqueous $\mathrm{HCl}$ and brine to remove the catalyst residue. The water layer was extracted with $\mathrm{CH}_{2} \mathrm{Cl}_{2}$ several times until the emulsion disappeared and the water layer got clear. The combined organic phase was dried over sodium sulfate $\left(\mathrm{Na}_{2} \mathrm{SO}_{4}\right)$, filtered, and concentrated at reduced pressure. (Yields typically: 95\%). ${ }^{1} \mathrm{H}$ NMR: $(300 \mathrm{MHz}$, $\left.\mathrm{CDCl}_{3}, 298 \mathrm{~K}\right): \delta=7.38-7.27(\mathrm{~m}), 7.24-7.11(\mathrm{~m}), 5.47-$ $5.26(\mathrm{~m}), 4.20-4.05(\mathrm{~m}), 2.10-1.87(\mathrm{~m}), 1.75-1.57(\mathrm{~m})$, 1.45-1.12 (m) ppm. ${ }^{31} \mathrm{P}\{\mathrm{H}\} \mathrm{NMR}\left(202 \mathrm{MHz}^{\mathrm{N}} \mathrm{CDCl}_{3}, 298\right.$ $\mathrm{K}): \delta=-6.10 \mathrm{ppm}$.

$P 1_{0.95}-\mathrm{CO}-P 2_{0.05}$. The reaction was carried out following the general procedure above with $\mathrm{M} 2(450 \mathrm{mg}, 1.12 \mathrm{mmol})$ and M1 (10.17 g, $21.24 \mathrm{mmol}$ ) for $24 \mathrm{~h}$ (yield: 92\%). ${ }^{1} \mathrm{H}$ NMR $\left(500 \mathrm{MHz}, \mathrm{CDCl}_{3}, 298 \mathrm{~K}\right) \delta=7.36-7.28(\mathrm{~m}), 7.24-7.12$ (m), 5.39-5.36 (m), 5.36-5.32 (m), 2.06-1.92 (m), 1.70$1.61(\mathrm{~m}), 1.38-1.18(\mathrm{~m}) \mathrm{ppm} .{ }^{31} \mathrm{P}\{\mathrm{H}\}$ NMR $(202 \mathrm{MHz}$, $\left.\mathrm{CDCl}_{3}, 298 \mathrm{~K}\right): \delta=0.85,-6.11 \mathrm{ppm}$.

$P 1_{0.80}$-CO- $P 2_{0.20}$. The reaction was carried out following the general procedure above with $\mathbf{M} 2(8.00 \mathrm{~g}, 19.87 \mathrm{mmol})$ and M1 (38.05 g, $79.49 \mathrm{mmol}$ ) for $46 \mathrm{~h}$ (yield: 94\%). ${ }^{1} \mathrm{H}$ NMR: $\left(300 \mathrm{MHz}, \mathrm{CDCl}_{3}, 298 \mathrm{~K}\right): \delta=7.38-7.28(\mathrm{~m}), 7.24-7.10$ (m), 5.45-5.30 (m), 4.20-4.06 (m), 4.06-3.92 (m), 2.09$1.86(\mathrm{~m}), 1.79-1.55(\mathrm{~m}), 1.48-1.14(\mathrm{~m}) \mathrm{ppm} .{ }^{13} \mathrm{C}$ NMR $(75$ $\left.\mathrm{MHz}, \mathrm{CDCl}_{3}, 298 \mathrm{~K}\right) \delta 130.32,129.86,129.65,124.90,120.00$, 119.94, 68.61, 68.52, 32.62, 30.27, 30.18, 29.66, 29.47, 29.41, 29.18, 29.10, 27.23, $25.38 \mathrm{ppm} .{ }^{31} \mathrm{P}\{\mathrm{H}\}$ NMR $(121 \mathrm{MHz}$, $\left.\mathrm{CDCl}_{3}, 298 \mathrm{~K}\right): \delta=1.14,-6.14$ ppm.

$P 1_{0.60}$-CO-P2 0.40 . The reaction was carried out following the general procedure above with $\mathbf{M} 2(17.00 \mathrm{~g}, 42.23 \mathrm{mmol})$ and M1 (30.32 g, $63.35 \mathrm{mmol}$ ) for $46 \mathrm{~h}$ (yield: 89\%). ${ }^{1} \mathrm{H}$ NMR: $\left(300 \mathrm{MHz}, \mathrm{CDCl}_{3}, 298 \mathrm{~K}\right): \delta=7.37-7.28(\mathrm{~m}), 7.24-7.10$ (m), 5.45-5.28 (m), 4.19-4.07 (m), 4.06-3.93 (m), 2.07$1.87(\mathrm{~m}), 1.75-1.57(\mathrm{~m}), 1.44-1.16(\mathrm{~m}) \mathrm{ppm} .{ }^{13} \mathrm{C}$ NMR (75 $\left.\mathrm{MHz}, \mathrm{CDCl}_{3}, 298 \mathrm{~K}\right) \delta=130.32,129.87,129.65,124.91$, 120.00, 119.94, 68.62, 68.53, 67.63, 32.61, 30.26, 30.17, 29.66,
29.47, 29.18, 29.10, 27.23, 25.45, 25.3 ppm. ${ }^{31} \mathrm{P}\{\mathrm{H}\}$ NMR $\left(121 \mathrm{MHz}, \mathrm{CDCl}_{3}, 298 \mathrm{~K}\right): \delta=1.04,-6.13 \mathrm{ppm}$.

Representative Procedure for the ADMET Bulk Polymerization of M2. P2. In a vacuum reactor, 2 (60 g, $149 \mathrm{mmol})$ was melted at $40{ }^{\circ} \mathrm{C}$ and then Hoveyda-Grubbs firstgeneration catalyst $(0.3 \mathrm{~mol} \%)$ was mixed under an argon atmosphere. Polymerization was carried out at reduced pressure [first membrane pump ( $5 \mathrm{~h}, 50 \mathrm{mbar})$ and then oil pump ( $1 \mathrm{mbar})]$ to remove ethylene gas evolving during the metathesis reaction at $65{ }^{\circ} \mathrm{C}$ for $1 \mathrm{~h}$ and $90{ }^{\circ} \mathrm{C}$ for $16-72 \mathrm{~h}$. The polymer was not further purified after synthesis (yield: quantitative). ${ }^{1} \mathrm{H}$ NMR: (300 $\mathrm{MHz}, \mathrm{CDCl}_{3} / \mathrm{CD}_{3} \mathrm{OD} 4: 2,298$ $\mathrm{K}): \delta=5.29-4.93(\mathrm{~m}), 3.90-3.57(\mathrm{~m}), 1.92-1.58(\mathrm{~m}), 1.55-$ $1.28(\mathrm{~m}), 1.30-0.75(\mathrm{~m}) \mathrm{ppm} .{ }^{13} \mathrm{C} \mathrm{NMR}\left(75 \mathrm{MHz}, \mathrm{CDCl}_{3} /\right.$ $\left.\mathrm{CD}_{3} \mathrm{OD} 4: 2,298 \mathrm{~K}\right) \delta=130.02,67.09,67.01,32.26,30.03$, 29.93, 29.33, 29.21, 29.13, 28.88, 28.82, $25.19 \mathrm{ppm} .{ }^{31} \mathrm{P}\{\mathrm{H}\}$ NMR (121 MHz, $\left.\mathrm{CDCl}_{3} / \mathrm{CD}_{3} \mathrm{OD} 4: 2,298 \mathrm{~K}\right): \delta=-0.06$, $-0.79,-1.32 \mathrm{ppm}$.

$P 1_{0.05}$-CO-P2 0.95 . The reaction was carried out following the general procedure above with $\mathbf{M} 2(8.00 \mathrm{~g}, 30.50 \mathrm{mmol})$ and M1 (543.2 mg, $1.61 \mathrm{mmol}$ ) for $20 \mathrm{~h}$ (yield: quantitative). ${ }^{1} \mathrm{H}$ NMR: $\left(300 \mathrm{MHz}, \mathrm{CDCl}_{3} / \mathrm{CD}_{3} \mathrm{OD} 5: 1,298 \mathrm{~K}\right): \delta=7.37-7.27$ (m), 7.20-7.11 (m), 5.44-5.24 (m), 4.16-4.06 (m), 4.05$3.88(\mathrm{~m}), 2.07-1.83(\mathrm{~m}), 1.77-1.53(\mathrm{~m}), 1.45-1.12(\mathrm{~m})$ ppm. ${ }^{31} \mathrm{P}\{\mathrm{H}\}$ NMR $\left(121 \mathrm{MHz}, \mathrm{CDCl}_{3} / \mathrm{CD}_{3} \mathrm{OD} 5: 1,298 \mathrm{~K}\right)$ : $\delta=0.03,-0.71,-1.19,-6.62 \mathrm{ppm}$.

Representative Procedure for Catalytic Hydrogenation. P1-H. A Schlenk flask was charged with P1 and dissolved in toluene (ca. $12 \mathrm{wt} \%$ ). The air was removed by reduced pressure and flushing the reactor with argon. $10 \% \mathrm{Pd} / \mathrm{C}$ catalyst (10 wt \%) was added, and the reactor was evacuated and flushed with hydrogen from a balloon. Hydrogenation was then performed with a hydrogen balloon under vigorous stirring at room temperature until ${ }^{1} \mathrm{H}$ NMR showed the removal of the double-bond signals. The solution was filtered over celite, and the polymer was obtained as a solid after solvent evaporation in a yield of $80 \% .{ }^{1} \mathrm{H}$ NMR: $(300 \mathrm{MHz}$, $\left.\mathrm{CDCl}_{3}, 298 \mathrm{~K}\right): \delta=7.38-7.27(\mathrm{~m}), 7.24-7.11(\mathrm{~m}), 5.47-$ $5.26(\mathrm{~m}), 4.20-4.05(\mathrm{~m}), 2.10-1.87(\mathrm{~m}), 1.75-1.57(\mathrm{~m})$, $1.45-1.12(\mathrm{~m})$ ppm. ${ }^{13} \mathrm{C} \mathrm{NMR}\left(176 \mathrm{MHz}, \mathrm{CDCl}_{3}, 298 \mathrm{~K}\right) \delta=$ $150.88,129.66,124.91,120.02,119.99,68.59,68.55,30.28$, $30.24,29.76,29.70,29.61,29.54,29.14,25.43$ ppm. ${ }^{31} \mathrm{P}\{\mathrm{H}\}$ NMR (283 MHz, $\left.\mathrm{CDCl}_{3}, 298 \mathrm{~K}\right): \delta=-6.10 \mathrm{ppm}$.

P1-H ${ }_{0.95}-\mathrm{CO}-\mathrm{P2}-\mathrm{H}_{0.05}$. Hydrogenation of $\mathbf{P} \mathbf{1}_{\mathbf{0 . 9 5}}-\mathbf{c o}-\mathbf{P 2} \mathbf{2}_{\mathbf{0 . 0 5}}$ (yield: 90\%). ${ }^{1} \mathrm{H}$ NMR (300 MHz, $\left.\mathrm{CDCl}_{3}, 298 \mathrm{~K}\right) \delta=$ 7.38-7.27 (m), 7.23-7.10 (m), 4.20-4.05 (m), 1.75-1.60 (m), 1.48-1.14 (m). ${ }^{13} \mathrm{C} \mathrm{NMR}(75 \mathrm{MHz}, \mathrm{CDCl} 3,298 \mathrm{~K}) \delta=$ $129.64,124.89,120.01,119.94,68.60,68.52,30.27,30.18$, 29.73, 29.68, 29.58, 29.51, 29.11, 25.39 ppm. ${ }^{31} \mathrm{P}\{\mathrm{H}\} \mathrm{NMR}$ $\left(121 \mathrm{MHz}, \mathrm{CDCl}_{3}, 298 \mathrm{~K}\right): \delta=-6.11 \mathrm{ppm}$.

P1- $\mathrm{H}_{0.80}-\mathrm{CO}-\mathrm{P2}-\mathrm{H}_{0.20}$. Hydrogenation of $\mathbf{P} \mathbf{1}_{\mathbf{0 . 8 0}}-\mathrm{co}-\mathbf{P} \mathbf{2}_{\mathbf{0 . 2 0}}$ (yield: 92\%). ${ }^{1} \mathrm{H}$ NMR: $\left(500 \mathrm{MHz}, \mathrm{CD}_{2} \mathrm{Cl}_{2}, 298 \mathrm{~K}\right): \delta=$ 7.38-7.31 (m), 7.22-7.14 (m), 4.18-4.04 (m), 4.02-3.90 (m), $1.72-1.56(\mathrm{~m}), 1.45-1.08(\mathrm{~m}) \mathrm{ppm} .{ }^{13} \mathrm{C} \mathrm{NMR}(126$ $\left.\mathrm{MHz}, \mathrm{CD}_{2} \mathrm{Cl}_{2}, 298 \mathrm{~K}\right) \delta=68.56,68.51,53.63,53.41,53.19$, 52.98, 30.25, 30.20, 29.74, 29.72, 29.68, 29.59, 29.52, 29.12, 25.41 ppm. ${ }^{31} \mathrm{P}\{\mathrm{H}\}$ NMR $\left(202 \mathrm{MHz}, \mathrm{CD}_{2} \mathrm{Cl}_{2}, 298 \mathrm{~K}\right): \delta=$ $0.77,-0.90,-6.22 \mathrm{ppm}$.

P1- $\mathrm{H}_{0.60}-\mathrm{CO}-\mathrm{P2}-\mathrm{H}_{0.40}$. Hydrogenation of $\mathbf{P} \mathbf{1}_{\mathbf{0 . 6 0}}-\mathrm{co}-\mathbf{P} \mathbf{2}_{\mathbf{0 . 4 0}}$. After filtration over celite, Soxhlet extraction with $\mathrm{CHCl}_{3}$ of celite and coal from the catalyst was necessary to increase the yield (yield: $81 \%$ ). ${ }^{1} \mathrm{H}$ NMR: $\left(500 \mathrm{MHz}, \mathrm{CD}_{2} \mathrm{Cl}_{2}, 298 \mathrm{~K}\right): \delta=$ 7.39-7.30 (m), 7.24-7.14 (m), 4.19-4.04 (m), 4.03-3.88 
(m), $1.72-1.57(\mathrm{~m}), 1.453-1.10(\mathrm{~m})$ ppm. ${ }^{13} \mathrm{C}$ NMR (75 $\left.\mathrm{MHz}, \mathrm{CDCl}_{3}, 298 \mathrm{~K}\right) \delta=129.65,124.90,120.01,119.94$, $68.63,68.54,30.27,30.18,29.72,29.51,29.11,25.39$ ppm. ${ }^{31} \mathrm{P}$ $\{\mathrm{H}\}$ NMR $\left(202 \mathrm{MHz}, \mathrm{CD}_{2} \mathrm{Cl}_{2}, 298 \mathrm{~K}\right): \delta=0.51,-6.23 \mathrm{ppm}$.

P2-H. P2 (2 g) was dissolved in $40 \mathrm{~mL}$ of toluene/methanol (7:3) at $40{ }^{\circ} \mathrm{C}$ and then transferred into a hydrogenation tube. The polymer solution was degassed for $10 \mathrm{~min}$ by bubbling argon under vigorous stirring. The hydrogenation catalyst precursor $[(\mathrm{PCy} 3) 3 \mathrm{Cl} 2 \mathrm{Ru}=\mathrm{CHOEt}](4.4 \mathrm{mg}$; synthesized from Grubbs first-generation catalyst with ethyl vinyl ether $)^{24}$ was added and the solution was again degassed for $2 \mathrm{~min}$. Hydrogenation was then performed in a high-pressure reactor at $40{ }^{\circ} \mathrm{C}$ and 60 bar $\mathrm{H}_{2}$ overnight. After hydrogenation, the solvent was removed under reduced pressure to give P2 in quantitative yield. NMR measurement was done by dissolving $0.1 \mathrm{~mL}$ of the reaction mixture before removing the solvent in $0.5 \mathrm{~mL}$ of $\mathrm{CDCl}_{3} / \mathrm{MeOD}$ (4:2). Dissolving P2-H again was not accessible for any tested solvent. ${ }^{1} \mathrm{H}$ NMR: $(300 \mathrm{MHz}$, $\left.\mathrm{CDCl}_{3} / \mathrm{CD}_{3} \mathrm{OD} 4: 2,298 \mathrm{~K}\right): \delta=3.89-3.70(\mathrm{~m}), 1.55-1.38$ (m), 1.28-0.82 (m) ppm. ${ }^{31} \mathrm{P}\{\mathrm{H}\}$ NMR (121 $\mathrm{MHz} \mathrm{CDCl}_{3} /$ $\left.\mathrm{CD}_{3} \mathrm{OD} 4: 2,298 \mathrm{~K}\right): \delta=3.28 \mathrm{ppm}$.

Esterification of P2 Units. P1-H $\mathbf{H}_{0.80}-$ co-P2- $\mathbf{H}_{0.20}(100 \mathrm{mg})$ was dissolved in $1.4 \mathrm{~mL}$ of chloroform and $0.6 \mathrm{~mL}$ of methanol at $35{ }^{\circ} \mathrm{C}$. Trimethylsilyldiazomethane $(2 \mathrm{M})$ in diethyl ether $(2$ equiv to $\mathrm{P}-\mathrm{OH}$ funct., $51 \mu \mathrm{L}, 0.5 \mathrm{mmol}$ ) was added, and the reaction mixture was stirred for $30 \mathrm{~min}$ at $25^{\circ} \mathrm{C}$. Solvents and excess trimethylsilyldiazomethane were removed at reduced pressure. ${ }^{1} \mathrm{H}$ NMR $\left(300 \mathrm{MHz}, \mathrm{CDCl}_{3}, 298 \mathrm{~K}\right) \delta=7.38-7.09$ (m), 4.18-4.08 (m), 4.08-3.93 (m), $3.75(\mathrm{~d}, J=12 \mathrm{~Hz})$, 1.79-1.47 (m), 1.44-1.08 (m) ppm. ${ }^{31} \mathrm{P}$ NMR (121 MHz, $\left.\mathrm{CDCl}_{3}, 298 \mathrm{~K}\right) \delta=0.40,-6.11 \mathrm{ppm}$.

\section{ASSOCIATED CONTENT}

\section{S Supporting Information}

The Supporting Information is available free of charge on the ACS Publications website at DOI: 10.1021/acsomega.9b01040.

DSC and TGA curves; X-ray diffractograms; shear lap test; NMR spectra; and GPC elugrams (PDF)

\section{AUTHOR INFORMATION}

\section{Corresponding Author}

*E-mail: wurm@mpip-mainz.mpg.de. Phone: 00496131 379581. Fax: 00496131370330.

\section{ORCID}

Kaloian Koynov: 0000-0002-4062-8834

Frederik R. Wurm: 0000-0002-6955-8489

\section{Notes}

The authors declare no competing financial interest.

\section{ACKNOWLEDGMENTS}

The authors thank Prof. Dr Katharina Landfester (MPIP) for continuous support. We also thank Andreas Hanewald (MPIP) for technical assistance with the rheological and stress-strain measurements and Alexander Kux (Henkel AG \& Co. KGaA) for technical assistance with shear lap tests. We thank Heraeus Medical for financial support and the Heraeus Medical team in Wehrheim (Germany) for experimental assistance. We thank Michael Steiert (MPIP) for the XRD measurements.

\section{REFERENCES}

(1) Binder, W. H.; Zirbs, R. Supramolecular Polymers and Networks with Hydrogen Bonds in the Main-and Side-Chain. In Hydrogen Bonded Polymers; Springer, 2006; pp 1-78.

(2) Folmer, B. J. B.; Sijbesma, R. P.; Versteegen, R. M.; van der Rijt, J. A. J.; Meijer, E. W. Supramolecular Polymer Materials: Chain Extension of Telechelic Polymers Using a Reactive HydrogenBonding Synthon. Adv. Mater. 2000, 12, 874-878.

(3) Aida, T.; Meijer, E. W.; Stupp, S. I. Functional Supramolecular Polymers. Science 2012, 335, 813-817.

(4) Lange, R. F. M.; Van Gurp, M.; Meijer, E. W. Hydrogen-bonded supramolecular polymer networks. J. Polym. Sci., Part A: Polym. Chem. 1999, 37, 3657-3670.

(5) Khlobystov, A. N.; Blake, A. J.; Champness, N. R.; Lemenovskii, D. A.; Majouga, A. G.; Zyk, N. V.; Schröder, M. Supramolecular design of one-dimensional coordination polymers based on silver(I) complexes of aromatic nitrogen-donor ligands. Coord. Chem. Rev. 2001, 222, 155-192.

(6) Steed, J. W.; Atwood, J. L. Supramolecular Chemistry; John Wiley \& Sons, 2013.

(7) Yan, X.; Wang, F.; Zheng, B.; Huang, F. Stimuli-responsive supramolecular polymeric materials. Chem. Soc. Rev. 2012, 41, 60426065 .

(8) Grabowski, S. J. Hydrogen Bonding: New Insights; Springer, 2006; Vol. 3.

(9) Yang, Y.; Urban, M. W. Self-healing polymeric materials. Chem. Soc. Rev. 2013, 42, 7446-7467.

(10) Zhao, Q.; Qi, H. J.; Xie, T. Recent progress in shape memory polymer: New behavior, enabling materials, and mechanistic understanding. Prog. Polym. Sci. 2015, 49-50, 79-120.

(11) Courtois, J.; Baroudi, I.; Nouvel, N.; Degrandi, E.; Pensec, S.; Ducouret, G.; Chanéac, C.; Bouteiller, L.; Creton, C. Supramolecular soft adhesive materials. Adv. Funct. Mater. 2010, 20, 1803-1811.

(12) Cangelosi, F.; Shaw, M. A review of hydrogen bonding in solid polymers: structural relationships, analysis, and importance. Polym.Plast. Technol. Eng. 1983, 21, 13-98.

(13) He, Y.; Zhu, B.; Inoue, Y. Hydrogen bonds in polymer blends. Prog. Polym. Sci. 2004, 29, 1021-1051.

(14) Król, P. Synthesis methods, chemical structures and phase structures of linear polyurethanes. Properties and applications of linear polyurethanes in polyurethane elastomers, copolymers and ionomers. Prog. Mater. Sci. 2007, 52, 915-1015.

(15) Marchildon, K. Polyamides-Still Strong After Seventy Years. Macromol. React. Eng. 2011, 5, 22-54.

(16) Xu, J.-F.; Chen, Y.-Z.; Wu, D.; Wu, L.-Z.; Tung, C.-H.; Yang, Q.-Z. Photoresponsive Hydrogen-Bonded Supramolecular Polymers Based on a Stiff Stilbene Unit. Angew. Chem., Int. Ed. 2013, 52, 97389742.

(17) Wang, H.; Ji, X.; Li, Z.; Zhu, C. N.; Yang, X.; Li, T.; Wu, Z. L.; Huang, F. Preparation of a white-light-emitting fluorescent supramolecular polymer gel with a single chromophore and use of the gel to fabricate a protected quick response code. Mater. Chem. Front. 2017, 1, 167-171.

(18) Zheng, Y.-R.; Tee, H. T.; Wei, Y.; Wu, X.-L.; Mezger, M.; Yan, S.; Landfester, K.; Wagener, K.; Wurm, F. R.; Lieberwirth, I. Morphology and Thermal Properties of Precision Polymers: The Crystallization of Butyl Branched Polyethylene and Polyphosphoesters. Macromolecules 2016, 49, 1321-1330.

(19) Bauer, K. N.; Liu, L.; Wagner, M.; Andrienko, D.; Wurm, F. R. Mechanistic study on the hydrolytic degradation of polyphosphates. Eur. Polym. J. 2018, 108, 286-294.

(20) Tee, H. T.; Lieberwirth, I.; Wurm, F. R. Aliphatic Long-Chain Polypyrophosphates as Biodegradable Polyethylene Mimics. Macromolecules 2019, 52, 1166-1172.

(21) Steinbach, T.; Wurm, F. R. Poly (phosphoester) s: a new platform for degradable polymers. Angew. Chem., Int. Ed. 2015, 54, 6098-6108. 
(22) Bauer, K. N.; Tee, H. T.; Velencoso, M. M.; Wurm, F. R. Mainchain poly (phosphoester) s: History, syntheses, degradation, bio-and flame-retardant applications. Prog. Polym. Sci. 2017, 73, 61-122.

(23) Marsico, F.; Wagner, M.; Landfester, K.; Wurm, F. R. Unsaturated Polyphosphoesters via Acyclic Diene Metathesis Polymerization. Macromolecules 2012, 45, 8511-8518.

(24) Ortmann, P.; Wimmer, F. P.; Mecking, S. Long-Spaced Polyketones from ADMET Copolymerizations as Ideal Models for Ethylene/CO Copolymers. ACS Macro Lett. 2015, 4, 704-707.

(25) Wunderlich, B. Macromolecular Physics, Volume 1: Crystal Structure, Morphology, Defects; Academic Press, 1973.

(26) Schwendeman, J. E.; Wagener, K. B. Modeling Ethylene/ Methyl Methacrylate and Ethylene/Methacrylic Acid Copolymers Using Acyclic Diene Metathesis Chemistry. Macromolecules 2004, 37, 4031-4037.

(27) Velencoso, M. M.; Battig, A.; Markwart, J. C.; Schartel, B.; Wurm, F. R. Molecular Firefighting-How Modern Phosphorus Chemistry Can Help Solve the Challenge of Flame Retardancy. Angew. Chem., Int. Ed. 2018, 57, 10450-10467.

(28) Lewis, C. L.; Dell, E. M. A review of shape memory polymers bearing reversible binding groups. J. Polym. Sci., Part B: Polym. Phys. 2016, 54, 1340-1364.

(29) Lendlein, A.; Jiang, H.; Junger, O.; Langer, R. Light-induced shape-memory polymers. Nature 2005, 434, 879.

(30) Jiang, H.; Kelch, S.; Lendlein, A. Polymers move in response to light. Adv. Mater. 2006, 18, 1471-1475.

(31) Liu, G.; Ding, X.; Cao, Y.; Zheng, Z.; Peng, Y. Shape memory of hydrogen-bonded polymer network/poly (ethylene glycol) complexes. Macromolecules 2004, 37, 2228-2232.

(32) Li, J.; Viveros, J. A.; Wrue, M. H.; Anthamatten, M. ShapeMemory Effects in Polymer Networks Containing Reversibly Associating Side-Groups. Adv. Mater. 2007, 19, 2851-2855.

(33) Fu, B.; Sun, X.; Qian, W.; Shen, Y.; Chen, R.; Hannig, M. Evidence of chemical bonding to hydroxyapatite by phosphoric acid esters. Biomaterials 2005, 26, 5104-5110.

(34) Fukegawa, D.; Hayakawa, S.; Yoshida, Y.; Suzuki, K.; Osaka, A.; Van Meerbeek, B. Chemical Interaction of Phosphoric Acid Ester with Hydroxyapatite. J. Dent. Res. 2006, 85, 941-944.

(35) Maege, I.; Jaehne, E.; Henke, A.; Adler, H.-J. P.; Bram, C.; Jung, C.; Stratmann, M. Self-assembling adhesion promoters for corrosion resistant metal polymer interfaces. Prog. Org. Coat. 1998, 34, 1-12. 